\title{
Recruitment and significance of Th22 cells and Th17 cells in malignant ascites
}

\author{
XIAN-WEN YANG, HAI-XING JIANG, RONGE LEI, WEI-SHUN LU, SHI-HUI TAN and SHAN-YU QIN \\ Department of Gastroenterology, The First Affiliated Hospital of Guangxi Medical University, \\ Nanning, Guangxi 530021, P.R. China
}

Received May 24, 2016; Accepted September 1, 2017

DOI: $10.3892 / \mathrm{ol} .2018 .9316$

\begin{abstract}
T helper (Th)22 and Th17 cells are implicated in the pathogenesis of a number of types of cancer. However, the function of Th22 and Th17 cells in malignant ascites (MA) remains unknown. The present study aimed at examining the distribution, phenotypes, recruitment, and prognostic value of Th22 and Th17 cells in MA from patients with hepatocellular carcinoma (HCC). A total of 26 patients with $\mathrm{HCC}$ with MA and 15 healthy controls were included in the present study. The proportion of Th22 cells, Th17 cells, C-C motif chemokine receptor (CCR)4, CCR6 and CCR10 were examined using flow cytometry. Interleukin (IL-)22, IL-17, C-C motif chemokine ligand (CCL)20, CCL22 and CCL27 were investigated using ELISA. In addition, the chemoattractant activity of chemokines for Th22 and Th17 cells in vitro were examined via a chemotaxis assay. The results of the present study demonstrated that Th22 cells, Th17 cells, IL-22 and IL-17 were significantly increased in MA compared with the corresponding blood and peripheral blood from healthy controls. Additionally, Th22 cells expressed increased concentrations of CCR6, CCR4 and CCR10, and Th17 cells expressed increased concentrations of CCR4 and CCR6 in MA compared with the corresponding blood. The chemotaxis assay revealed that CCL20/CCR6, CCL22/CCR4 and CCL27/CCR10 were responsible for the recruitment of Th22 cells into MA, whereas CCL22/CCR4 was responsible for the recruitment of Th17 cells. Furthermore, the patients with an increased number of Th17 cells exhibited an increased survival time compared with patients with a limited number of Th17 cells. Th22 and Th17 cells serve an important function in the development of MA, and the accumulation of Th22 and Th17 cells in MA may be due to a local increase in proinflammatory cytokines and chemokines. Increased Th17
\end{abstract}

Correspondence to: Dr Shan-Yu Qin, Department of Gastroenterology, The First Affiliated Hospital of Guangxi Medical University, 6 Shuang-Yong Road, Nanning, Guangxi 530021, P.R. China

E-mail: qsy0511@163.com

Key words: $\mathrm{T}$ helper 22 cells, $\mathrm{T}$ helper 17 cells, chemokines, hepatocellular carcinoma, malignant ascites cell numbers in MA may indicate the improvement of patient survival.

\section{Introduction}

Malignant ascites (MA) is a pathological condition due to tumor cell invasion and metastasis to the abdominal cavity. The appearance of MA indicates progression of cancer, poor quality of life and decreased life expectancy for patients (1). Hepatocellular carcinoma (HCC), gastric cancer and ovarian cancer typically lead to the occurrence of MA (2). Similar to other types of immune microenvironment, MA contains a large number of lymphocytes, particularly cluster of differentiation (CD) $4^{+} \mathrm{T}$ helper (Th) lymphocytes, tumor cells and other types of immune cell (3). $\mathrm{CD}^{+} \mathrm{T}$ cells may inhibit the $\mathrm{T}$ cell response to exogenous- and auto-antibodies to maintain their own composition of immune tolerance in the tumor and prevent the body mounting an immune response. In addition, $\mathrm{CD}^{+} \mathrm{T}$ cells participate in tumor growth and metastasis via the secretion of a variety of soluble inflammatory, and immune factors (4).

Th22 cells have been identified as a novel $\mathrm{CD}^{+} \mathrm{T}$ cell subset, and primarily secrete interleukin (IL-)22, IL-6 and IL-1 $\beta$, but not IL-17 or interferon (IFN-) $\gamma$ (5). IL-22 is the effector cytokine of Th22 cells and belongs to the IL-10 cytokine family (6). Th22 cells and IL-22 has been implicated in the pathogenesis of liver cancer (7). In addition, the overexpression of IL-22 in primary tumor tissue and malignant pleural effusion may be involved in the occurrence, and progression of lung cancer (8). Furthermore, Th17 cells are a novel subset of $\mathrm{CD}^{+} \mathrm{T}$ cells and produce IL-17, but not IFN- $\gamma$ (9). Th17 cells serve a dominant function in a variety of autoimmune diseases and cancers, including rheumatoid arthritis and gastric cancer $(10,11)$. An increased number of Th17 cells have been observed in patients with lung cancer exhibiting malignant pleural effusion $(12,13)$. In a previous study of multiple sclerosis lesions and lung inflammation, it was demonstrated that IL-22 and IL-17 increased vascular endothelial permeability $(14,15)$. However, studies regarding the function of Th22 and Th17 cells in MA is limited, and the biological function of Th22 and Th17 cells in MA remains unknown. Therefore, the aim of the present study was to investigate the distribution and the phenotypic characteristics of Th22 and Th17 cells in patients with HCC. The present study additionally aimed to 
determine the molecular mechanism underlying the recruitment of peritoneal Th22 and Th17 cells into MA in patients with HCC. Finally, the prognostic value of peritoneal Th17 and Th22 cells was examined in patients with MA.

\section{Patients and methods}

Patients. The present study was approved by the Ethics Committee of the First Affiliated Hospital of Guangxi Medical University for human studies and all patients provided written informed consent. MA samples were selected from 26 patients with newly diagnosed HCC with MA (AJCC stage IV) at The First Affiliated Hospital of Guangxi Medical University (Nanning, China) between February 2013 and December 2015. The mean age of the patients was $53.7 \pm 7.6$ years. In addition, 15 healthy volunteers as controls (mean age, $50.9 \pm 5.5$ years) during the same period were recruited in the present study. A diagnosis of MA was established by the demonstration of malignant cells in peritoneal effusion and/or in closed peritoneal biopsy specimen. The patients were excluded if they had received any invasive procedures directed into the peritoneal cavity or if any abdominal trauma had occurred within 3 months prior to hospitalization. No patients received antitumor treatment and or glucocorticoid or other non-steroidal anti-inflammatory drugs prior to participating in the present study. The clinical information for the MA patients and healthy controls are summarized in Table I.

Sample collection and processing. Within $24 \mathrm{~h}$ of hospitalization, between 400 and $800 \mathrm{ml}$ MA samples were selected from each patient and placed in heparinization tubes, using a standard abdominocentesis technique, and $10 \mathrm{~mm}$ peripheral blood was drawn. The MA specimens were immersed in ice immediately and subsequently centrifuged at $800 \mathrm{xg}$ for $10 \mathrm{~min}$ at $4^{\circ} \mathrm{C}$. The supernatants of MA and plasma were frozen at $-80^{\circ} \mathrm{C}$ immediately for use in subsequent experiments. The cell pellets of MA were resuspended in PBS and mononuclear cells were isolated using Ficoll-Hypaque gradient centrifugation (Solarbio, Beijing, China) at $4^{\circ} \mathrm{C}, 800 \mathrm{xg}$ to determine the $\mathrm{T}$ cell subsets within $1 \mathrm{~h}$.

Flow cytometry. Following surface or intracellular staining with anti-human-specific antibodies (Abs) conjugated with Peridinin-Chlorophyll-protein (PerCP)-cysteine (cy)5.5, allophycocyanin (APC), phycoerythrin (PE), Alexa Fluor (AF)647, AF488 or fluorescein isothiocyanate (FITC). The expression of markers on $\mathrm{T}$ cells from MA and peripheral blood were determined using flow cytometry as previously described (12). The human Abs against anti-CD4, -IL-22, -IL-17A and -IFN- $\gamma$ were purchased from BD Biosciences (Franklin Lakes, NJ, USA; cat. nos. 561844, 12-7229-41, 559502 and 551221, respectively). Human antibodies against -C-C motif chemokine receptor (CCR)4, -CCR6 and -CCR10 were purchased from Thermo Fisher Scientific, Inc. (Waltham, MA, USA; cat. nos. PA5-11866, CSB-E04660h and 720308). The anti-CD4, -IL-22, -IL-17A and -IFN- $\gamma$ were diluted at 1:200, and the CCR4,-CCR6 and-CCR10 were diluted at 1:500.Intracellular staining for IL-22 or IL-17 was performed on T cells stimulated with phorbol myristate acetate $(50 \mathrm{ng} / \mathrm{ml}$; Sigma-Aldrich; Merck KGaA, Darmstadt, Germany) and ionomycin $(1 \mu \mathrm{g} / \mathrm{ml}$; Sigma-Aldrich; Merck KGaA) in the presence of GolgiStop
Table I. Characteristics of the participants included in the present study.

\begin{tabular}{lcc}
\hline Index & $\begin{array}{c}\text { Patients with MA, } \\
\mathrm{n}=26\end{array}$ & $\begin{array}{c}\text { Healthy controls, } \\
\mathrm{n}=15\end{array}$ \\
\hline Sex, male/female & $15 / 11$ & $8 / 7$ \\
Age, years & $53.7 \pm 7.6$ & $50.9 \pm 5.5$ \\
CRP in plasma, mg/l & $62.6 \pm 15.4$ & $8.1 \pm 1.2$ \\
AST, U/l & $78.7 \pm 11.3$ & $20.6 \pm 6.1$ \\
ALT, U/l & $68.9 \pm 9.4$ & $18.5 \pm 7.4$ \\
Protein, $\mathrm{g} / \mathrm{ml}$ & $4.1 \pm 0.4$ & \\
LDH, U/l & $747.3 \pm 125.6$ & \\
AFP, $\mu \mathrm{g} / 1$ & $81.7 \pm 10.6$ & \\
CEA, $\mu \mathrm{g} / \mathrm{l}^{\mathrm{a}}$ & $43.5 \pm 2.4$ & \\
\hline
\end{tabular}

Data are presented as the mean \pm standard deviation. CRP, C-reactive protein; LDH, lactate dehydrogenase; AST, aspartate aminotransferase; ALT, alanine aminotransferase; AFP, alpha fetoprotin; CEA, carcinoembryonic antigen; MA, malignant ascites. ${ }^{\text {aT }}$ The control data were not included in this test.

(1.7 ug/ml; BD Biosciences) at $4^{\circ} \mathrm{C}$ for $5 \mathrm{~h}$, and subsequently stained with PerCP-cy5.5-CD4, PE-CCR4, FITC-CCR6 or PE-CCR10 at room temperature in the dark for $30 \mathrm{~min}$. Cells were washed twice with staining buffer ( $1 \mathrm{ml} /$ wash for tubes) and pellet by centrifugation $(250 \mathrm{x} \mathrm{g})$. Cells were resuspended in $250 \mu 1$ tubes of Fixation/Permeabilization solution (BD Biosciences) for $20 \mathrm{~min}$ at $4^{\circ} \mathrm{C}$. Cells were washed two times in 1X BD Perm/Wash ${ }^{\mathrm{TM}}$ buffer (1 ml/wash for staining in tubes). The cells were stained with APC or PE-IL-22, AF647-IL-17A and AF488-IFN- $\gamma$ at $4^{\circ} \mathrm{C}$ for $30 \mathrm{~min}$, following fixation $(100 \mu \mathrm{l}$ of Fixation Buffer and pulse vortex) at $4^{\circ} \mathrm{C}$ in the dark room for $20 \mathrm{~min}$. The permeabilization was performed according to the manufacturer's protocol. Mouse immunoglobulin G irrelevant isotype control (BD Biosciences; cat. no. MAB0032; dilution 1:100) served as isotype control. Stained cells were washed 2 times with $1 \mathrm{x}$ BD Perm/Wash ${ }^{\mathrm{TM}}$ buffer $(1 \mathrm{ml} / \mathrm{tubes})$, resuspend in Staining Buffer and subsequently analyzed by flow cytometric analysis using BD FCSDiva Software and FCS Epress 4 software (De Novo Software, Los Angeles, CA).

ELISA. MA and peripheral blood specimens were collected into heparinization tubes. The cell-free supernatants of MA and plasma were obtained from all subjects by centrifugation $800 \mathrm{x} \mathrm{g}$ for $10 \mathrm{~min}$ at room temperature and stored at $-80^{\circ} \mathrm{C}$ immediately for determination of cytokines. The concentration of cytokines IL-22 and IL-17, chemokines C-C motif chemokine ligand (CCL)20, CCL22 and CCL27 in MA, and plasma were determined using an ELISA kit (cat. no. CSB-E09125h; R\&D Systems, Inc., minneapolis, MN, USA,) in accordance with the manufacturer's protocol (lower detection limit $1 \mathrm{pg} / \mathrm{ml}$; eBioscience; Thermo Fisher Scientific, Inc.). All samples were assayed in duplicate.

Chemotaxis assay of Th22 and Th17 cells in vitro. The chemotaxis assay was observed using light microscope with magnification of $\times 200$. Briefly, the $8-\mu \mathrm{m}$ pore polycarbonate 
filters in 24-well Transwell chambers (Corning Incorporated, Corning, NY, USA) were used. Transwell membranes were coated with fibronectin $(5 \mu \mathrm{g} / \mathrm{ml}$; Chemicon International; EMD Millipore, Billerica, MA, USA) for $30 \mathrm{~min}$ at $37^{\circ} \mathrm{C}$. Purified CD4 ${ }^{+} \mathrm{T}$ cells from blood $\left(2 \times 10^{5}\right)$ were isolated using an EasySep ${ }^{\mathrm{TM}}$ Direct Human CD4+ T Cell Isolation kit (StemCell Technologies Inc., Vancouver, BC, Canada), then added into the top chamber and resuspended in RPMI-1640 medium (Gibco; Thermo Fisher Scientific, Inc.) with $0.5 \%$ fetal bovine serum (Gibco; Thermo Fisher Scientific, Inc.) (final volume, $100 \mu \mathrm{l}$ ). MA supernatants were placed in the bottom chamber in a volume of $600 \mu \mathrm{l}$ and the chambers were incubated at $37^{\circ} \mathrm{C}$ in an atmosphere containing $5 \% \mathrm{CO}_{2}$ for $3 \mathrm{~h}$. Finally, all the cells that migrated into the bottom chamber were harvested, intracellularly stained for IL-22 or IL-17 and analyzed using flow cytometry as aforementioned. The chemotaxis index for Th22 and Th17 cells was calculated individually as follows: (Number of cells that migrated in response to MA or supernatants)/(number of cells that migrated in response to medium alone). To investigate whether CCL20, CCL22 and CCL27 contributed to Th22 or Th17 cell migration, inhibition experiments were performed by mixing the MA or supernatants with $100 \mathrm{ng} / \mathrm{ml}$ anti-CCL20 mAb (cat. no. 500-M28), anti-CCL22 mAb (cat. no. MAB336), anti-CCL27 mAb (cat. no. MAB376) or mouse immunoglobulin $\mathrm{G}$ irrelevant isotype control (cat. no. MAB0032) (R\&D systems, Inc., Minneapolis, MN, USA), the anti-body was diluted for 1:100, and incubated at $4^{\circ} \mathrm{C}$ for $20 \mathrm{~min}$.

Survival analysis for MA patients. To estimate the survival time of MA patients with different Th22 or Th17 cell, the patients were divided into cell high group or cell low group based on the median value of cell. The median value of Th17 cells and Th22 cells was $2.75,3.02 \%$, respectively, and patient had the median value was considered in high group in this study.

Statistical analysis. Data are expressed as the mean \pm standard deviation. Comparisons of Th22, Th17, CCL20, CCL22, CCL27, IL-17 and IL-22 levels in MA, corresponding blood and peripheral blood from healthy controls were determined using a one-way analysis of variance (ANOVA). Newman-Keuls multiple comparison test (q test) was used to determine the difference between two groups when the one-way ANOVA analysis indicated a significant difference. Comparsion of Th22, Th17, CCL20, CCL22, CCL27, IL-17 and IL-22 levels in MA and corresponding blood was determined using Student's t-test. The Pearson or Spearman correlation test was used for correlation analysis, depending on the data distribution. Overall survival was estimated using the Kaplan-Meier method and compared using the log-rank test. Analysis was performed using SPSS version 16.0 statistical software (SPSS, Inc., Chicago, IL, USA) and $\mathrm{P}<0.05$ was considered to indicate a statistically significant difference.

\section{Results}

Th22, Th17 and Th1 cells are increased in MA. It is reported that Th22 cells are associated with Th17 (16) and Th1 cells (17); therefore, in the present study, the distribution of Th22, Th17 and Th1 cells were studied in patients with MA, and healthy controls. Representative flow cytometry scatter plots of Th22, Th17 and Th1 cells in MA, and healthy controls are presented in Fig. 1A. The proportions of Th22 cells exhibited significantly increased values in MA in comparison with the corresponding peripheral blood and healthy controls. In addition, Th17 and Th1 cells in MA were significantly increased compared with the corresponding peripheral blood and healthy controls (Fig. 1B). The proportions of peritoneal Th22 cells were positively associated with Th17 or Th1 cells, and Th17 cells were positively associated with Th1 cells in MA (all $\mathrm{P}<0.01$; Fig. 1C).

Th22 and Th17 cells exhibit similar phenotypic characteristics in MA and peripheral blood samples. The flow cytometry scatter plots of the expression levels of CCR4, CCR6 and CCR10 on Th22 cells in MA, and the corresponding peripheral blood are presented in Fig. 2A. The phenotypic analysis revealed that Th22 cells expressed high concentrations of CCR4, CCR6 and CCR10 in MA compared with the corresponding peripheral blood (Fig. 2B). The expression levels of CCR4 and CCR6 in Th17 cells from MA, and the peripheral blood are presented in Fig. 3A. The results revealed that Th17 cells expressed high concentrations of CCR4 (Fig. 3B) and CCR6 (Fig. 3C) in MA compared with the corresponding peripheral blood.

Chemokines CCL20, CCL22 and CCL27 are increased in MA, and may be associated with the migration of Th17 and Th22 cells. The concentrations of chemokines CCL20, CCL22 and CCL27 in MA were significantly increased, compared with that in the corresponding peripheral blood, determined using ELISA (Fig. 4A-C), which are receptors for CCR4, CCR6, and CCR10, respectively. On the basis of these results, it was hypothesized that peripheral Th22 and Th17 cells may infiltrate into the peritoneal cavity in response to these chemokines. In the chemotaxis assays, it was revealed that the anti-CCL20, anti-CCL22 and anti-CCL27 mAbs significantly suppressed Th22 cell migration; whereas, the anti-CCL20 mAb markedly inhibited Th17 cell migration (Fig. 4D and E).

Increased concentrations of IL-22 and IL-17 in MA. The concentration of IL-22 was significantly increased in MA, compared with the corresponding peripheral blood and healthy controls, determined using ELISA (Fig. 5A). Additionally, the concentration of IL-17 was significantly increased in MA compared with that in the corresponding peripheral blood and healthy controls (Fig. 5B). There was a positive association identified between Th22 cells and the concentrations of IL-22 in MA (Fig. 5C). Furthermore, there was a positive association revealed between IL-22 and Th17 cells in MA ( $\mathrm{P}=0.001$; Fig. 5D). However, no association was identified between IL-22 and Th22 or Th17 cells in either the peripheral blood or healthy controls (all $\mathrm{P}>0.05$; data not shown).

Increased number of Th17 cells indicates an increased overall survival time. On the basis of the median value of Th17 cells 
A
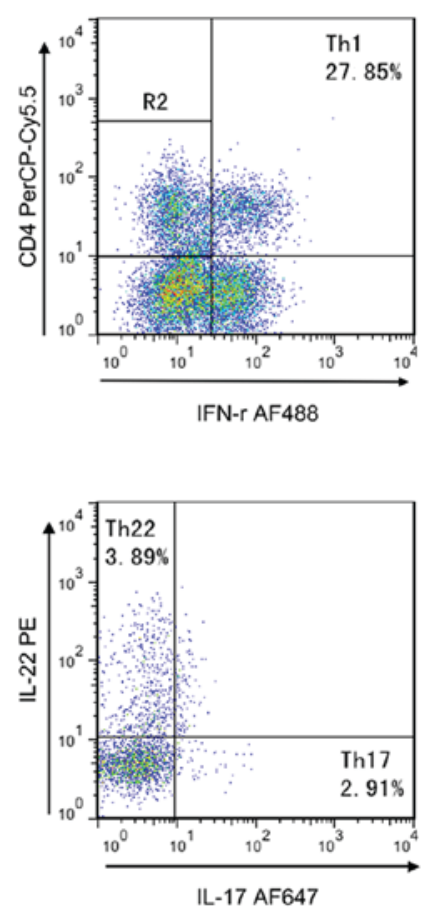

B

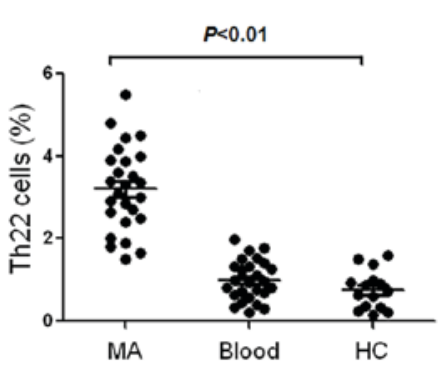

C

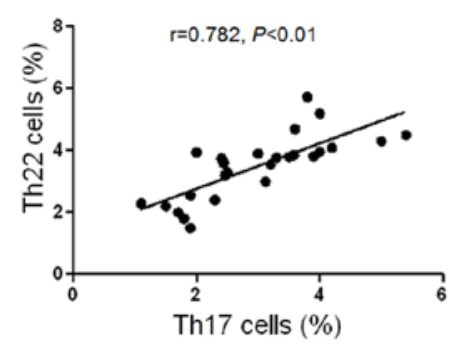

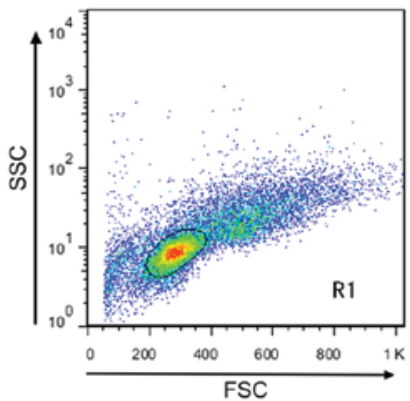
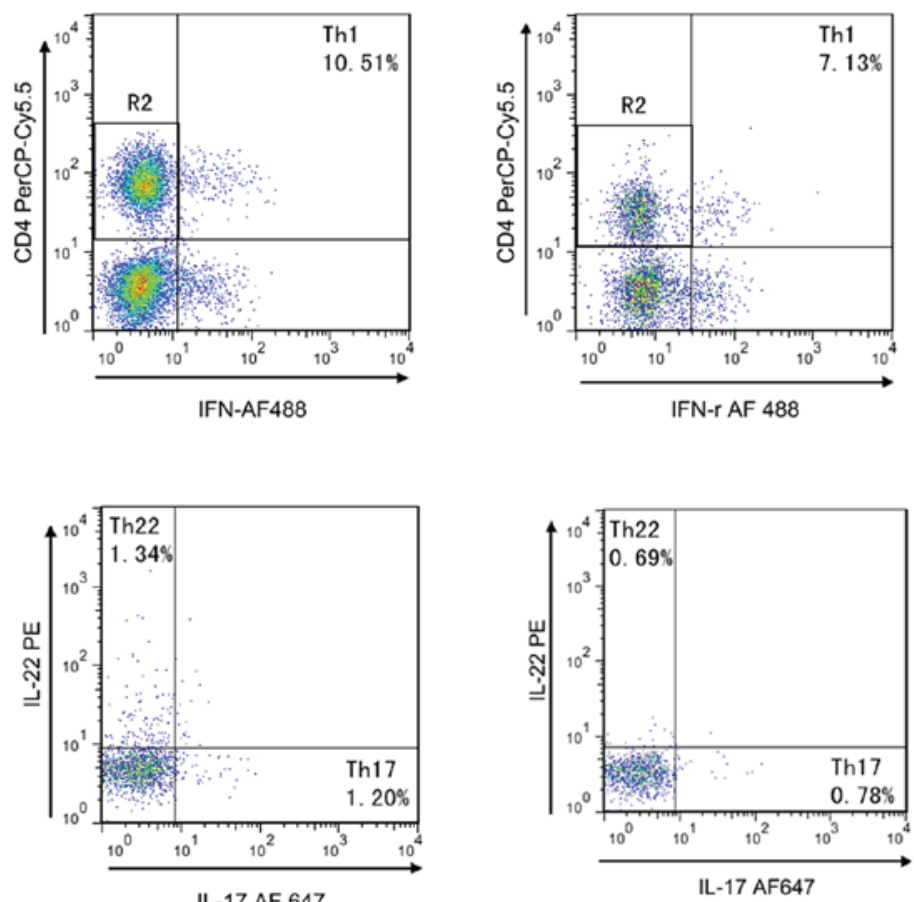

IL-17 AF 647
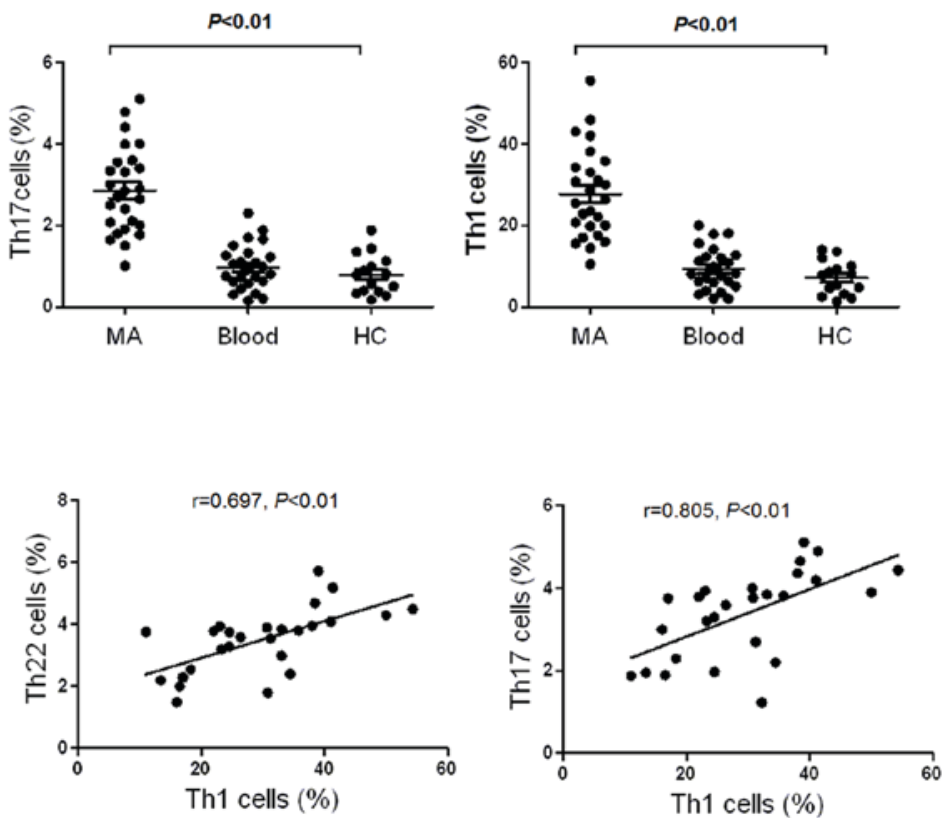

Figure 1. Distribution of Th22, Th17 and Th1 cells in MA, corresponding peripheral blood and HC. (A) Anti-CD4 monoclonal antibodies were performed with gating on $\mathrm{CD}_{4}{ }^{+} \mathrm{T}$ cells for further testing Th22, Th17 and Th1 cells. The typical flow cytometry scatter plots of Th22 cells, Th17 cells and Th1 cells in MA, Blood and HC are presented. (B) Comparisons between the proportion of Th22, Th17, and Th1 in MA, Blood and HC. Horizontal line in the graph represents the mean. The proportion of Th cells were determined using flow cytometry. (C) Th22 cells were positively associated with Th17 cells or Th1 cells in MA. Th17 cells were positively associated with Th1 cells in MA. Th, Thelper cell; MA, malignant ascites; HC, healthy controls; CD, cluster of differentiation; PE, phycoerythrin; PerCP cy5.5, Peridinin-Chlorophyll-protein-cysteine 5.5; IFN, interferon; AF, Alexa Fluor; FSC, forward scatter; SSC, side scatter. 

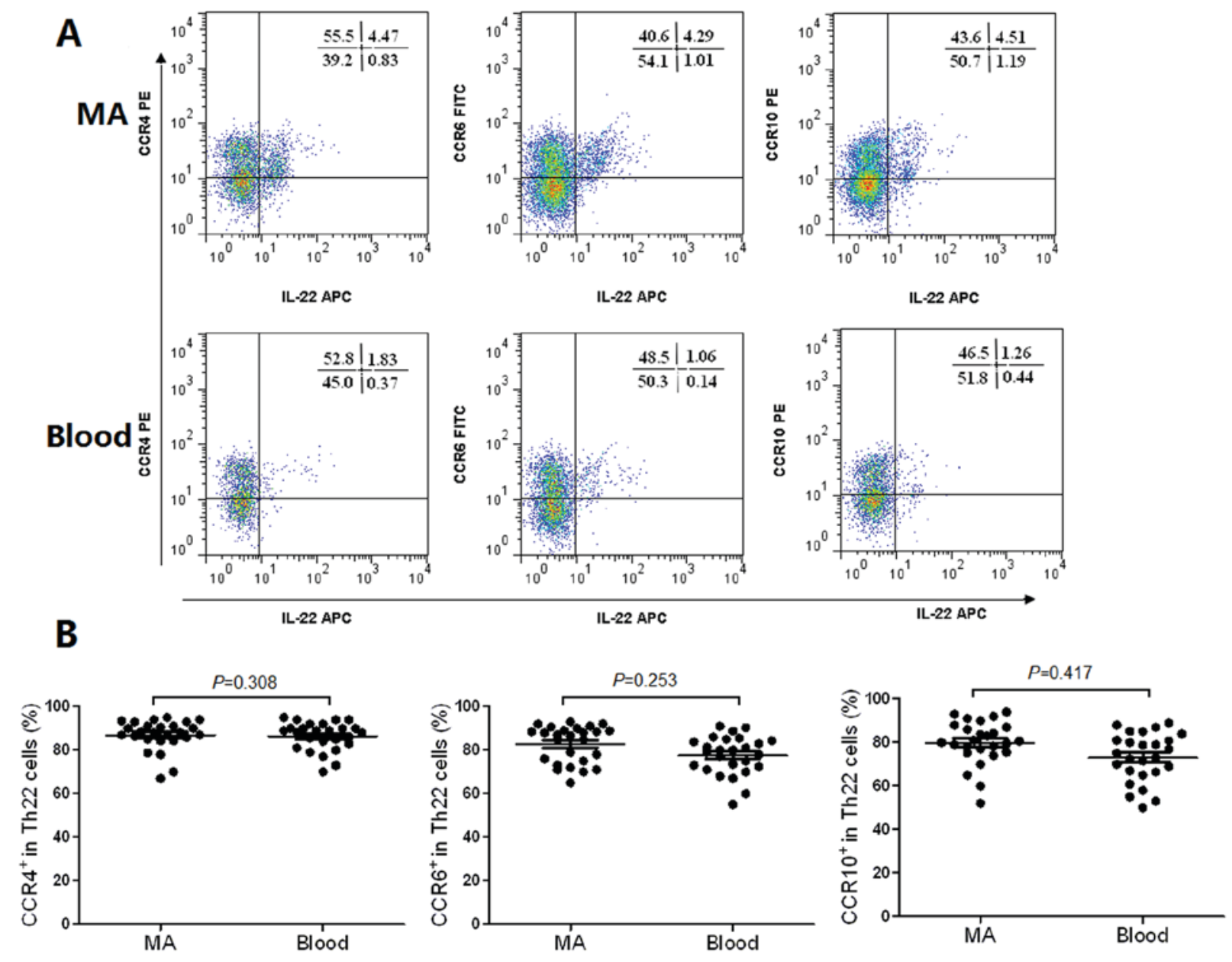

Figure 2. Phenotypic characteristics of Th22 cells in MA and their corresponding peripheral blood (Blood). (A) The typical flow cytometry scatter plots demonstrating the expression of CCR4, CCR6 and CCR 10 on Th22 cells from MA and blood. (B) Comparisons between the proportion of CCR4 $4^{+}$, CCR6 ${ }^{+}$and $\mathrm{CCR} 10^{+}$cells in total Th22 cells in MA and blood. Th, Thelper cell; MA, malignant ascites; CCR, C-C motif chemokine receptor; PE, phycoerythrin; APC, allophycocyanin.

(2.75\%), the 26 patients with MA were divided into either the Th17 cell high group $(n=13)$ and Th17 cell low group $(n=13)$. As presented in Fig. 6A, patients with in the high Th17 cell group exhibited an increased overall survival time, compared with that in the low Th17 cell group [hazard ratio (HR), 1.75; $95 \%$ confidence interval $(\mathrm{CI}), 1.29-2.21 ; \mathrm{P}=0.012]$. The median Th22 cells value was $3.02 \%$; however, no significant difference was identified between the Th22 cell high group $(n=13)$ and the Th22 cells low group $(n=13)$ (HR, 0.48; 95\% CI, 0.19-1.23; $\mathrm{P}=0.127$ ) (Fig. 6B).

\section{Discussion}

To the best of our knowledge, the present study was the first to investigate the distribution, the phenotypic characteristics and the recruitment of Th22, and Th17 cells in patients with HCC and MA. The results of the present study demonstrated that the proportion of Th22 and Th17 cells were significantly increased in MA compared with the corresponding peripheral blood and healthy controls, indicating the involvement of Th22 and Th17 cells in the development of MA. In addition, there was a positive association identified between IL-22 and Th22 cells, Th17 cells in MA, suggesting that Th22 and Th17 cells may have a similar effect through the regulation of IL-22.
However, the association between Th 22 and Th17 cells requires additional study.

IL-22 and IL-17 may induce Th cell differentiation, and IL-22 may be more widely involved in IFN- $\gamma$-producing $\mathrm{CD}^{+} \mathrm{T}$ cell (Th1 cell)-mediated immune responses (15). Furthermore, it is IL-22, not IL-17, that may induce wound-healing responses, and tissue-repair protecting from tuberculosis $(13,18)$. IL-22 is predominantly secreted by Th22, Th17 and Th1 cells (19). Additionally, of the IL-22-producing T cells, the proportion of Th22 cells accounts for between 37 and $63 \%$, Th17 cells accounts for between 10 and $18 \%$, and Th1 cells accounts for $\sim 35 \%$ (20). It has been demonstrated that IL- 6 promotes the expression of IL-22, and is required for IL-17 induction from naïve $\mathrm{T}$ cells $(21,22)$; this may explain the positive association between the concentration of peritoneal IL-22 and the number of peritoneal Th22 cells, and the positive association between IL-22 and Th17 cells identified in the present study. In addition, the results of the present study indicated that proinflammatory cytokines in MA may promote the secretion of IL-22.

Some mechanism has been identified to increase the number of Th22 and Th17 cells. In addition to the local generation and differentiation, the reason for the increase in peritoneal Th22 and Th17 cells may have been in response to 

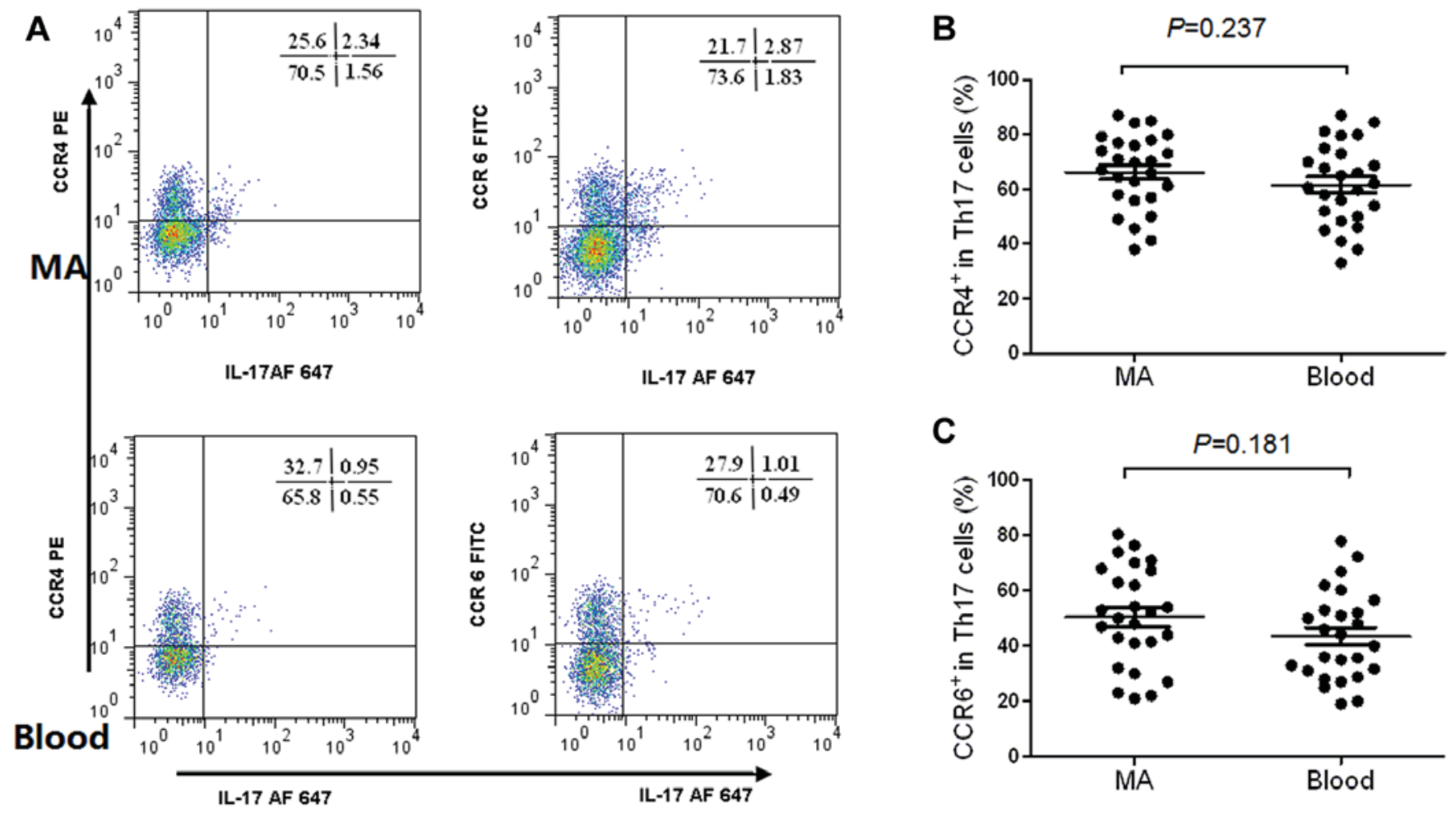

Figure 3. Phenotypic characteristics of Th17 cells in MA and their corresponding peripheral blood. (A) The typical flow cytometry scatter plots revealed that the expression of CCR4 and CCR6 on Th17 cells from MA and blood. (B and C) Comparisons of the proportion of CCR4 ${ }^{+}$and CCR6 ${ }^{+}$cells in total Th17 cells in MA and peripheral blood. MA, malignant ascites; Th, T helper cell; CCR, C-C motif chemokine receptor; IL, interleukin; PE, phycoerythrin; FITC, fluorescein isothiocyanate; AF, Alexa Fluor.
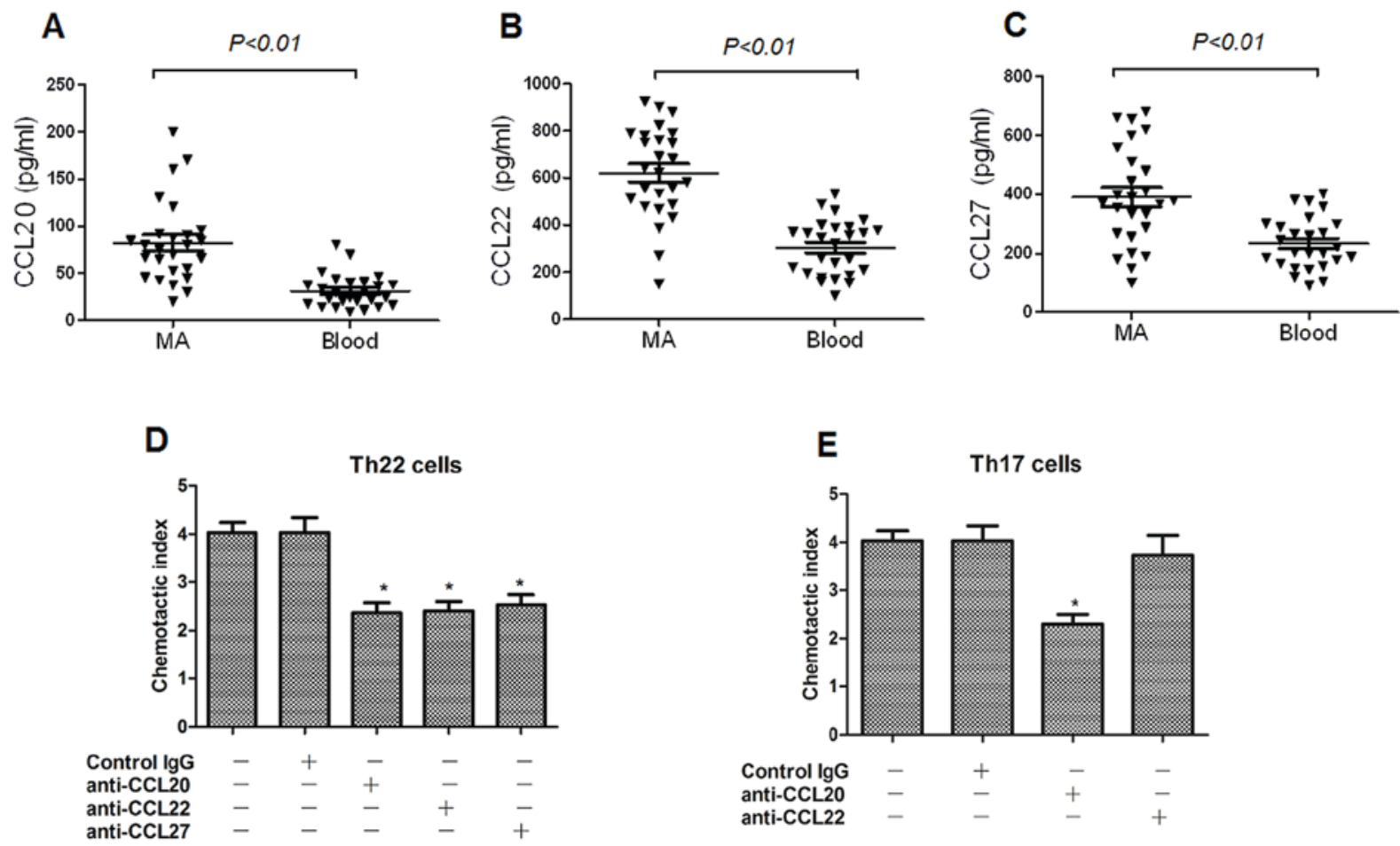

Figure 4. Concentrations of CCL20, CCL22 and CCL27 in MA and their corresponding peripheral blood (Blood). The concentrations of (A) CCL20,(B) CCL22 and (C) CCL27 were significantly increased in MA compared with corresponding peripheral blood. MA were used to stimulate chemotaxis of (D) Th22 and (E) Th17 cells in the absence or presence of anti-CCL20, anti-CCL22 and anti-CCL27 mAb or an irrelevant isotype control. CCL, C-C motif chemokine ligand; MA, malignant ascites; Th, T helper cell; mAb, monoclonal antibody; IgG, immunoglobulin $\mathrm{G}$. * $\mathrm{P}<0.05$ vs. blank control and IgG control.

recruitment from the peripheral blood (13). A previous study demonstrated that the migration of lymphocytes is regulated by the chemokine/chemokine receptor axis (23). CCL20/CCR6,

CCL22/CCR4 and CCL27/CCR10 chemotaxis axes have been 

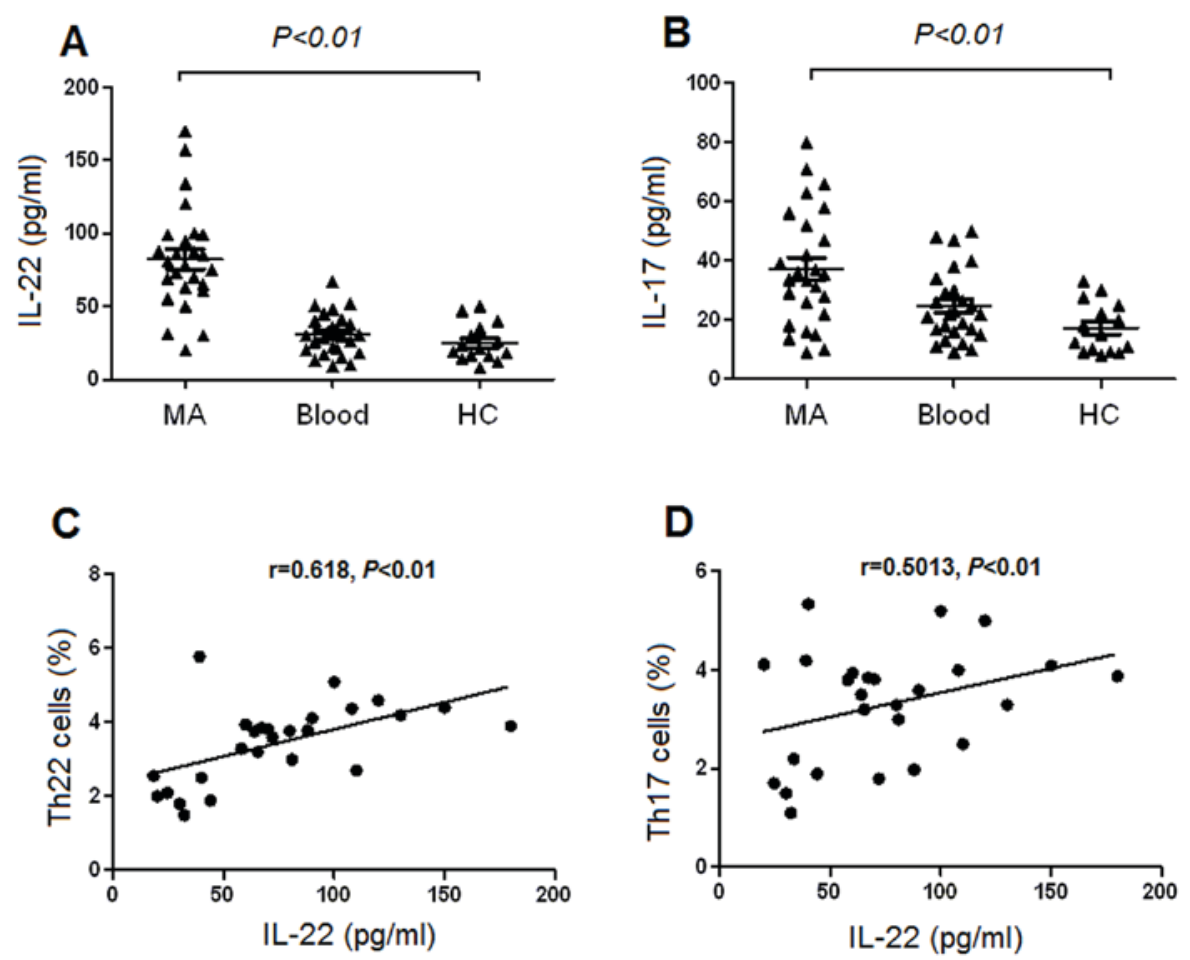

Figure 5. Concentrations of IL-22 and IL-17 in malignant ascites (MA), those corresponding blood and HC. The concentrations of (A) IL-22 and (B) IL-17 ware significantly increased in MA compared with blood and HC. Positive associations were identified between (C) Th22 cells and IL-22, and between (D) Th17 cells and Il-22 in MA. IL, interleukin; MA, malignant ascites; HC, healthy controls; blood, peripheral blood; Th, Thelper cell.

identified to serve functions in the recruitment of lymphocytes to local tissues (24). Previously studies have demonstrated that the recruitment of Th9 cells into malignant pleural effusion may be induced by pleural CCL20 (25), and that CCL20 and CCL22 were responsible for the recruitment of IL-27-producing $\mathrm{CD} 4^{+} \mathrm{T}$ cells to tuberculous pleural effusion $(13,18)$. However, the function of the chemokine/chemokine receptor interaction in the recruitment of peripheral Th22 cells and Th17 cells into MA remain unknown.

In the phenotypic analysis of the present study, the results revealed that Th22 cells expressed increased concentrations of CCR4, CCR6 and CCR10, whereas Th17 cells expressed increased concentrations of CCR4, and CCR6 in MA compared with the corresponding peripheral blood. In addition, the concentrations of CCL20, CCL22 and CCL27 in MA were markedly increased, compared with those in the plasma from corresponding peripheral blood. These results indicated that the axes of CCL20/CCR6, CCL22/CCR4 and CCL27/CCR10 may be involved in the recruitment of Th22, and Th17 cells to the peritoneal cavity from the peripheral blood. Using chemotaxis assays, it was observed that, by inhibiting the CCL20/CCR6, CCL22/CCR4 and CCL27/CCR10 axes, the migration rate of Th22 cells was significantly suppressed, and inhibition of CCL20/CCR6 prevented Th17 cell migration, indicating that these chemotaxis axes may be responsible for the recruitment of peripheral Th22 and Th17 cells into MA.

Previously, it was reported that high expression of IL-17 was associated with poor prognosis, whereas high Th17 cell frequencies were associated with improved prognosis (26). Th17 cells are a subpopulation of IL-17+ cells and exhibit a distinct association with prognosis compared with total IL-17 (27). Th17 cells serve an antitumor function in antitumor

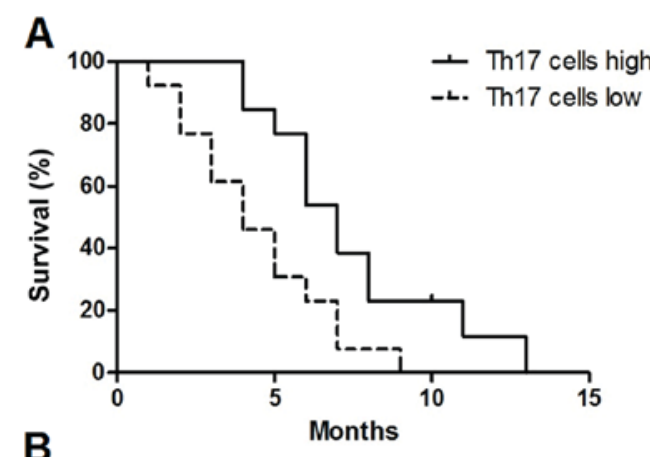

B

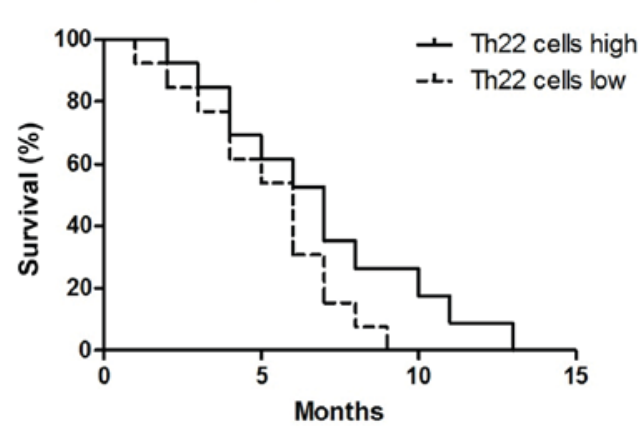

Figure 6. Prognostic value of peritoneal Th17 and Th22 cells in patients with MA. (A) Increased Th17 cells predicts improved survival in patients with MA. (B) No significant difference was identified in MA patients with high or low Th22 cells. Overall survival was estimated using the Kaplan-Meier method and compared using the log-rank test. Th, T helper cell; MA, malignant ascites.

immunity and promote the immune response of tumor-specific cytotoxic $\mathrm{T}$ cells in the pulmonary melanoma model (28). Accumulation of Th17 cells in malignant pleural effusion 
indicates the improvement of patient survival (12) and a decrease in Th17 cells in ascites from patients with ovarian cancer indicated a poor prognosis (29). Similar to these aforementioned studies, the present study demonstrated that the accumulation of Th17 cells in MA indicated the improvement of patient survival.

Th22 cells accumulate in a number of different types of tumor, compared with healthy tissues, and the patient outcome may differ from one tumor type to another (30). Previous studies have demonstrated that increased Th22 cells were associated with poor prognosis of patients with pancreatic cancer (31), multiple myeloma (32) and colorectal cancer (33); however, Th22 cells are protective in colorectal cancer (34). In the present study, no significant different was identified in the survival time between the Th22 cell high and Th22 cell low groups of patients. Therefore, it was hypothesized that the different prognostic functions of Th22 and Th17 cells may be due to the cytokines secreted by the different cell types or the tumor type, including HCC or ovarian cancer at stage III or IV; however, the underlying molecular mechanisms require additional study.

The results of the present study demonstrated that Th22 and Th17 cells may serve functions in the pathogenesis of MA, and accumulation of Th22 cells and Th17 cells in MA may be due to locally increased proinflammatory cytokines and chemokines. Furthermore, increased numbers of Th17 cells in MA indicates an improved survival time for patients with HCC. However, due to the limited number of samples included, a study with larger umber samples is warranted, and an in vivo animal experiment to further validate these results is needed.

\section{Acknowledgements}

Not applicable.

\section{Funding}

The present study was partially supported by the Guangxi Natural Science Foundation (grant no. 2014GXNSFAA118203). The funders had no role in study design, data collection and analysis, decision to publish or preparation of the manuscript.

\section{Availability of data and materials}

The datasets used and/or analyzed during the current study are available from the corresponding author on reasonable request.

\section{Authors' contributions}

SYQ and HXJ designed the study, interpreted the experimental results and modified the manuscript. XWY, RL and WSL collected the samples and performed the experiment. XWY and SHT performed statistical analysis. All authors have read and approved the manuscript.

\section{Ethics approval and consent to participate}

The present study was approved by the Ethics Committee of the First Affiliated Hospital of Guangxi Medical University for human studies and all patients provided written informed consent.

\section{Patient consent for publication}

Not applicable.

\section{Competing interests}

The authors declare that they have no competing interests.

\section{References}

1. Smith EM and Jayson GC: The current and future management of malignant ascites. Clin Oncol (R Coll Radiol) 15: 59-72, 2003.

2. Adam RA and Adam YG: Malignant ascites: Past, present, and future. J Am Coll Surg 198: 999-1011, 2004.

3. Hao C, Shi Y, Yu J, Wei X, Li S and Tong Z: The therapeutic function of the chemokine RANTES on the H22 hepatoma ascites model. Mol Cell Biochem 367: 93-102, 2012.

4. Zhang N, Pan HF and Ye DQ: Th22 in inflammatory and autoimmune disease: Prospects for therapeutic intervention. Mol Cell Biochem 353: 41-46, 2011.

5. Eyerich K, Pennino D, Scarponi C, Foerster S, Nasorri F, Behrendt H, Ring J, Traidl-Hoffmann C, Albanesi C and Cavani A: IL-17 in atopic eczema: Linking allergen-specific adaptive and microbial-triggered innate immune response. J Allergy Clin Immunol 123: 59-66.e4, 2009.

6. Dumoutier L, Louahed J and Renauld JC: Cloning and characterization of IL-10-related T cell-derived inducible factor (IL-TIF), a novel cytokine structurally related to IL-10 and inducible by IL-9. J Immunol 164: 1814-1819, 2000.

7. Qin S, Ma S, Huang X, Lu D, Zhou Y and Jiang H: Th22 cells are associated with hepatocellular carcinoma development and progression. Chin J Cancer Res 26: 135-141, 2014.

8. Zhang W, Chen Y, Wei H, Zheng C, Sun R, Zhang J and Tian Z: Antiapoptotic activity of autocrine interleukin-22 and therapeutic effects of interleukin-22-small interfering RNA on human lung cancer xenografts. Clin Cancer Res 14: 6432-6439, 2008.

9. Bettelli E, Korn T, Oukka M and Kuchroo VK: Induction and effector functions of T(H)17 cells. Nature 453: 1051-1057, 2008.

10. Bettelli E, Korn T and Kuchroo VK: Th17: The third member of the effector T cell trilogy. Curr Opin Immunol 19: 652-657, 2007.

11. Guéry L and Hugues S: Th17 cell plasticity and functions in cancer immunity. Biomed Res Int 2015: 314620, 2015.

12. Ye ZJ, Zhou Q, Gu YY, Qin SM, Ma WL, Xin JB, Tao XN and Shi HZ: Generation and differentiation of IL-17-producing CD4+ $\mathrm{T}$ cells in malignant pleural effusion. J Immunol 185: 6348-6354, 2010.

13. Ye ZJ, Zhou Q, Yuan ML, Du RH, Yang WB, Xiong XZ, Huang B and Shi HZ: Differentiation and recruitment of IL-22-producing helper $\mathrm{T}$ cells stimulated by pleural mesothelial cells in tuberculous pleurisy. Am J Respir Crit Care Med 185: 660-669, 2012.

14. Kebir H, Kreymborg K, Ifergan I, Dodelet-Devillers A, Cayrol R, Bernard M, Giuliani F, Arbour N, Becher B and Prat A: Human TH17 lymphocytes promote blood-brain barrier disruption and central nervous system inflammation. Nat Med 13: 1173-1175, 2007.

15. You QH, Sun GY, Wang N, Shen JL and Wang Y: Interleukin-17F-induced pulmonary microvascular endothelial monolayer hyperpermeability via the protein kinase $\mathrm{C}$ pathway. J Surg Res 162: 110-121, 2010.

16. Liang SC, Tan XY, Luxenberg DP, Karim R, Dunussi-Joannopoulos K, Collins M and Fouser LA: Interleukin (IL)-22 and IL-17 are coexpressed by Th17 cells and cooperatively enhance expression of antimicrobial peptides. J Exp Med 203: 2271-2279, 2006.

17. Volpe E, Touzot M, Servant N, Marloie-Provost MA, Hupé P, Barillot E and Soumelis V: Multiparametric analysis of cytokine-driven human Th17 differentiation reveals a differential regulation of IL-17 and IL-22 production. Blood 114: 3610-3614, 2009.

18. Ye ZJ, Xu LL, Zhou Q, Cui A, Wang XJ, Zhai K, Wang Z, Tong ZH and Shi HZ: Recruitment of IL-27-producing CD4(+) $T$ cells and effect of IL-27 on pleural mesothelial cells in tuberculous pleurisy. Lung 193: 539-548, 2015. 
19. Trifari S, Kaplan CD, Tran EH, Crellin NK and Spits $H$ Identification of a human helper $\mathrm{T}$ cell population that has abundant production of interleukin 22 and is distinct from $\mathrm{T}(\mathrm{H})-17$, $\mathrm{T}(\mathrm{H}) 1$ and $\mathrm{T}(\mathrm{H}) 2$ cells. Nat Immunol 10: 864-871, 2009.

20. Duhen T, Geiger R, Jarrossay D, Lanzavecchia A and Sallusto F: Production of interleukin 22 but not interleukin 17 by a subset of human skin-homing memory T cells. Nat Immunol 10: 857-863,2009.

21. Zheng Y, Danilenko DM, Valdez P, Kasman I, Eastham-Anderson $\mathrm{J}, \mathrm{Wu} \mathrm{J}$ and Ouyang W: Interleukin-22, a $\mathrm{T}(\mathrm{H}) 17$ cytokine, mediates IL-23-induced dermal inflammation and acanthosis. Nature 445: 648-651, 2007.

22. Nishihara M, Ogura H, Ueda N, Tsuruoka M, Kitabayashi C, Tsuji $\mathrm{F}$, Aono $\mathrm{H}$, Ishihara $\mathrm{K}$, Huseby $\mathrm{E}$, Betz UA, et al: IL-6-gp130-STAT3 in T cells directs the development of IL-17+ Th with a minimum effect on that of Treg in the steady state. Int Immunol 19: 695-702, 2007.

23. Moser B and Loetscher P: Lymphocyte traffic control by chemokines. Nat Immunol 2: 123-128, 2001.

24. Xiao C, Zhou Q, Li X, Li H, Meng T, Zhong Y, Pu J, Zhu M, Xu Y, Gan L, et al: Differentiation and recruitment of IL-22-producing helper T cells in lgA nephropathy. Am J Transl Res 8: 3872-3882, 2016.

25. Bu XN, Zhou Q, Zhang JC, Ye ZJ, Tong ZH and Shi HZ: Recruitment and phenotypic characteristics of interleukin 9-producing CD4+ T cells in malignant pleural effusion. Lung 191: 385-389, 2013.

26. Liao R, Sun J, Wu H, Yi Y, Wang JX, He HW, Cai XY, Zhou J, Cheng YF, Fan J and Qiu SJ: High expression of IL-17 and IL-17RE associate with poor prognosis of hepatocellular carcinoma. J Exp Clin Cancer Res 32: 3, 2013.

27. Punt S, Langenhoff JM, Putter H, Fleuren GJ, Gorter A and Jordanova ES: The correlations between IL-17 vs. Th17 cells and cancer patient survival: A systematic review. Oncoimmunology 4 e984547, 2015.
28. Martin-Orozco N, Muranski P, Chung Y, Yang XO, Yamazaki T, Lu S, Hwu P, Restifo NP, Overwijk WW and Dong C: T helper 17 cells promote cytotoxic $\mathrm{T}$ cell activation in tumor immunity. Immunity 31: 787-798, 2009.

29. Kryczek I, Banerjee M, Cheng P, Vatan L, Szeliga W, Wei S, Huang E, Finlayson E, Simeone D, Welling TH, et al: Phenotype, distribution, generation, and functional and clinical relevance of Th17 cells in the human tumor environments. Blood 114: 1141-1149, 2009.

30. Jia $\mathrm{L}$ and Wu C: The biology and functions of Th22 cells. Adv Exp Med Biol 841: 209-230, 2014.

31. Niccolai E, Taddei A, Ricci F, Rolla S, D'Elios MM, Benagiano M, Bechi P, Bencini L, Ringressi MN, Pini A, et al: Intra-tumoral IFN- $\gamma$-producing Th 22 cells correlate with TNM staging and the worst outcomes in pancreatic cancer. Clin Sci (Lond) 130: 247-258, 2016.

32. Di Lullo G, Marcatti M, Heltai S, Brunetto E, Tresoldi C, Bondanza A, Bonini C, Ponzoni M, Tonon G, Ciceri F, et al: Th22 cells increase in poor prognosis multiple myeloma and promote tumor cell growth and survival. Oncoimmunology 4: e1005460, 2015

33. Huang YH, Cao YF, Jiang ZY, Zhang S and Gao F: Th22 cell accumulation is associated with colorectal cancer development. World J Gastroenterol 21: 4216-4224, 2015.

34. Ling L, Zhao P, Yan G, Chen M, Zhang T, Wang L and Jiang Y. The frequency of Th17 and Th22 cells in patients with colorectal cancer at pre-operation and post-operation. Immunol Invest 44: 56-69, 2015. 